\title{
Polyimide-Derived Carbon-Coated $\mathrm{Li}_{4} \mathrm{Ti}_{5} \mathrm{O}_{12}$ as High-Rate Anode Materials for Lithium Ion Batteries
}

\author{
Shih-Chieh Hsu ${ }^{1} \mathbb{D}$, Tzu-Ten Huang ${ }^{2} \mathbb{D}$, Yen-Ju Wu ${ }^{3} \mathbb{D}$, Cheng-Zhang Lu ${ }^{4}$, Huei Chu Weng ${ }^{5, * \mathbb{D}}$, \\ Jen-Hsien Huang ${ }^{6}$, Cai-Wan Chang-Jian ${ }^{7, *}$ and Ting-Yu Liu ${ }^{8, *(D)}$
}

1 Department of Chemical and Materials Engineering, Tamkang University, No. 151, Yingzhuan Road, Tamsui District, New Taipei City 25137, Taiwan; roysos@mail.tku.edu.tw

2 National Synchrotron Radiation Research Center, 101 Hsin-Ann Road, Hsinchu Science Park, Hsinchu 30076, Taiwan; huang.ty@nsrrc.org.tw

3 International Center for Young Scientists (ICYS), National Institute for Materials Science (NIMS), 1-2-1 Sengen, Tsukuba, Ibaraki 305-0047, Japan; WU.YenJu@nims.go.jp

4 Material and Chemical Research Laboratories, Industrial Technology Research Institute, No. 195, Chung Hsing Road, Chutung, Hsinchu 31040, Taiwan; chengzhanglu@itri.org.tw

5 Department of Mechanical Engineering, Chung Yuan Christian University, No. 200, Chungpei Road, Chungli District, Taoyuan City 32023, Taiwan

6 Department of Green Material Technology, Green Technology Research Institute, CPC Corporation, No. 2, Zuonan Rd., Nanzi District, Kaohsiung City 81126, Taiwan; 295604@cpc.com.tw

7 Department of Mechanical and Automation Engineering, I-Shou University, No.1, Sec. 1, Syuecheng Rd., Dashu District, Kaohsiung City 84001, Taiwan

8 Department of Materials Engineering, Ming Chi University of Technology, 84 Gungjuan Road, Taishan District, New Taipei City 24301, Taiwan

check for updates

Citation: Hsu, S.-C.; Huang, T.-T.; Wu, Y.-J.; Lu, C.-Z.; Weng, H.C.; Huang, J.-H.; Chang-Jian, C.-W.; Liu, T.-Y. Polyimide-Derived Carbon-Coated $\mathrm{Li}_{4} \mathrm{Ti}_{5} \mathrm{O}_{12}$ as High-Rate Anode Materials for Lithium Ion Batteries. Polymers 2021, 13, 1672. https://doi.org/10.3390/ polym 13111672

Academic Editor: Vito Di Noto

Received: 25 April 2021

Accepted: 19 May 2021

Published: 21 May 2021

Publisher's Note: MDPI stays neutral with regard to jurisdictional claims in published maps and institutional affiliations.

Copyright: (c) 2021 by the authors. Licensee MDPI, Basel, Switzerland. This article is an open access article distributed under the terms and conditions of the Creative Commons Attribution (CC BY) license (https:// creativecommons.org/licenses/by/ $4.0 /)$.
* Correspondence: hcweng@cycu.edu.tw (H.C.W.); cwchangjian@isu.edu.tw (C.-W.C.-J.); tyliu0322@gmail.com (T.-Y.L.); Tel.: +886-3-2654311 (H.C.W.); +886-7-6577711 (ext. 3231) (C.-W.C.-J.); +886-2-29089899 (ext. 4456) (T.-Y.L.)

\begin{abstract}
Carbon-coated $\mathrm{Li}_{4} \mathrm{Ti}_{5} \mathrm{O}_{12}$ (LTO) has been prepared using polyimide (PI) as a carbon source via the thermal imidization of polyamic acid (PAA) followed by a carbonization process. In this study, the PI with different structures based on pyromellitic dianhydride (PMDA), 4,4'-oxydianiline (ODA), and $p$-phenylenediamine ( $p$-PDA) moieties have been synthesized. The effect of the PI structure on the electrochemical performance of the carbon-coated LTO has been investigated. The results indicate that the molecular arrangement of PI can be improved when the rigid $p$-PDA units are introduced into the PI backbone. The carbons derived from the $p$-PDA-based PI show a more regular graphite structure with fewer defects and higher conductivity. As a result, the carbon-coated LTO exhibits a better rate performance with a discharge capacity of $137.5 \mathrm{mAh} / \mathrm{g}$ at $20 \mathrm{C}$, which is almost 1.5 times larger than that of bare LTO $(94.4 \mathrm{mAh} / \mathrm{g})$.
\end{abstract}

Keywords: $\mathrm{Li}_{4} \mathrm{Ti}_{5} \mathrm{O}_{12}$; polyimide; carbon coating; lithium ion battery; rate performance

\section{Introduction}

With the continuous depletion of fossil fuels and associated increasing air pollution, it is essential to raise the proportion of renewable energy supplies. However, renewable energy sources such as wind and solar are intermittent and cannot be stockpiled without energy storage systems (ESSs). ESSs based on lithium ion batteries (LIBs) are emerging as one of the key solutions to effectively integrate high shares of variable renewable energy due to their high energy density, zero memory effect and long lifespan [1]. By introducing an EES into the power generation system, it can smooth the output of wind or solar power generation, and reduce the impact on the power grid. Unfortunately, most of the anode and cathode materials suffer from low electronic conductivity and poor ionic diffusivity in the lattice resulting in poor rate capability. Therefore, the rate performance of the active materials must be further improved for use in voltage regulation and frequency modulation. 
To address the above issue, alien ion doping [2], the building of a nanoporous structure [3,4] and surface coating [5-7] have proven to be effective for improving the rate performance by narrowing the band gap, shortening migration paths for $\mathrm{Li}^{+}$ions and reduction of interfacial resistance, respectively. Among these approaches, the surface coating is a feasible strategy to improve the LIB performance due to the multi-functional advantages such as enhancement of electric conductivity [8], structural stability [9] and offering a physical protection to avoid side reactions with the electrolyte [10]. Several compounds have been proposed to be an efficient coating layer such as carbon-based materials [11,12], metal oxides/hydroxides [13,14], phosphide-based materials [15] and glass-based materials [16]. Among these candidates, carbon coating is one of the most effective and facile ways to improve the electrochemical performance of LIB materials due to its excellent electron conductivity, low cost, and superior chemical/electrochemical stability. Compared with the metal oxide coating, carbon coating can easily form a smooth and uniform thin layer with high surface coverage on the active materials. Moreover, the carbon coating layer can also serve as a buffer layer to accommodate the dimensional variation of the active material during the lithiation and delithiation process leading to improved structural stability [17].

Recently, polyimide (PI) has been found to be a high-quality carbon source for the synthesis of graphene [18,19] and highly conductive carbon [20], because of the abundant hexagonal crystalline carbon within the imide structures. The obtained PI derived graphene reveals remarkable conductivity and electrochemical properties, which are useful for various applications e.g., supercapacitors [21], sensors [22], electrocatalysts [23] and electrothermal heaters [24]. Therefore, polyimide is expected to be suitable for forming the conductive carbon layer of LIB materials. It has been reported that the carbon films derived from PI with different structures can show quite different physical properties and graphite microstructure. However, the effect of carbon coating derived from different PIs on the LIB performance is still unclear.

In this study, two different PIs have been prepared from pyromellitic dianhydride (PMDA), 4,4'-oxydianiline (ODA) and $p$-phenylenediamine ( $p$-PDA). By introducing the rigid planar moiety ( $p$-PDA) into the main chain of classical PMDA/ODA PI (PO-PI), the PMDA/ODA/ $p$-PDA PI (POP-PI) shows an increased crystallinity and orientation degree. Here, we used the PO-PI and POP-PI as carbon sources to modify the $\mathrm{Li}_{4} \mathrm{Ti}_{5} \mathrm{O}_{12}$ (LTO) anode material, followed by thermal treatment to obtain the carbon-coated LTO materials. The results indicate that the uniformly coated carbon layer on LTO can reduce its resistance and polarization leading to better rate performance and the corresponding electrochemical properties. Moreover, with incorporation of the rigid $p$-PDA segment, the carbon derived from the POP-PI exhibits better molecular packing and less defect. As a result, the carbon-coated LTO prepared from the POP-PI can display an even better kinetic performance than that obtained from the PO-PI.

\section{Experimental Section}

\subsection{Material}

The monomers ODA (97\%), $p$-PDA (98\%) and PMDA (97\%) were purchased from Jinyu Co., Ltd. (Kaohsiung, Taiwan). The $\mathrm{TiO}_{2}(85 \%$, anatase, Hombikat 8602$)$ and $\mathrm{Li}_{2} \mathrm{CO}_{3}$ ( $\geq 99 \%$, Aldrich) used for the synthesis of LTO were purchased from World Chem Industries Co., Ltd. (Taipei, Taiwan) and Sigma Aldrich (St. Louis, MI, USA), respectively.

2.2. Preparation of Pyromellitic Dianhydride/4,4'-Oxydianiline Polyimide (PMDA/ODA PI) and $P M D A / O D A / p-P h e n y l e n e d i a m i n e(p-P D A) P I$

In this study, the PI precursor, poly(amic acid) (PAA) was obtained through the two-steps synthesis method from its monomers. First, the ODA monomer or mixed ODA/ $p$-PDA (1:1) were dissolved in $N$-methyl-2-pyrrolidone (NMP). Then, equimolar PMDA was added in the diamine solution under continuous stirring at $25^{\circ} \mathrm{C}$ with a solid content of $15 \mathrm{wt} \%$ to produce the PAA solution. Here, the PAAs prepared from PMDA/ODA and PMDA/ODA/ $p$-PDA are 
denoted as PO-PAA and POP-PAA, respectively. The PAA was then cast on glass substrate by doctor blade coating, s followed by soft baking at $80{ }^{\circ} \mathrm{C}$ for $60 \mathrm{~min}$. The soft-baked precursor films were thermally imidized $\left(150{ }^{\circ} \mathrm{C}\right.$ for $30 \mathrm{~min}, 250{ }^{\circ} \mathrm{C}$ for $30 \mathrm{~min}, 350{ }^{\circ} \mathrm{C}$ for $60 \mathrm{~min}$ and $400^{\circ} \mathrm{C}$ for $30 \mathrm{~min}$ ) under $\mathrm{N}_{2}$ atmosphere to obtain the PMDA/ODA PI and PMDA/ODA/p-PDA PI denoted herein as PO-PI and POP-PI, respectively.

\subsection{Preparation of Carbon-Coated $\mathrm{Li}_{4} \mathrm{Ti}_{5} \mathrm{O}_{12}$ (LTO)}

The carbon-coated LTO powders were prepared by spray drying precursor solution of lithium titanium peroxide, followed by solid-state calcination. Firstly, the $\mathrm{TiO}_{2}$ and $\mathrm{Li}_{2} \mathrm{CO}_{3}$ were dispersed in de-ionized water with a Li:Ti molar ratio $4: 5$ and a solid content of $15 \mathrm{wt} \%$. The solution was ball milled for $12 \mathrm{~h}$ to produce the homogenous slurry, which was fed to a pilot spray dryer (OHKAWARA KAKOHKI, model L-8i, No. 145874). The spherical LTO precursor obtained was added to the PMDA/ODA or PMDA/ODA/ $p$-PDA PAA solution, which was then stirred for $60 \mathrm{~min}$ and subsequently centrifuged. The centrifuged powders were dried in vacuum at $80^{\circ} \mathrm{C}$. Finally, the samples were thermally annealed via a stepwise process $\left(150{ }^{\circ} \mathrm{C}\right.$ for $30 \mathrm{~min}, 250{ }^{\circ} \mathrm{C}$ for $30 \mathrm{~min}, 350{ }^{\circ} \mathrm{C}$ for $60 \mathrm{~min}, 400{ }^{\circ} \mathrm{C}$ for $30 \mathrm{~min}, 500{ }^{\circ} \mathrm{C}$ for $60 \mathrm{~min}$ and $800^{\circ} \mathrm{C}$ for $120 \mathrm{~min}$ ). The modified LTO prepared from PO- and POP-PI are denoted herein as PO-LTO and POP-LTO, respectively. For the preparation of the bare LTO sample, the spray-dried precursor was directly annealed with the same heating program.

\subsection{Characterization}

The crystal structure of the sample was characterized by X-ray powder diffraction (XRD, Philips X'Pert/MPD instrument, El Dorado County, CA, USA). The morphologies were monitored by scanning electron microscopy (SEM, JEOL JSM-6701F, Tokyo, Japan) and transmission electron microscopy (TEM, JEOL 2010, Tokyo, Japan). The absorption measurement was taken using a Cintra 2020 (GBC scientific equipment, Australia) spectrophotometer. The differential scanning calorimetry (DSC) was measured on DSC 2500 (TA instrument, Lukens Drive, New Castle, DE, USA). Thermal gravimetric analysis (TGA) was carried out using a TGA 8000 (PerkinElmer, Boston, MS, USA). Functional group and chemical composition were characterized by using Fourier transform infrared (FTIR, PerkinElmer, Boston, MS, USA) spectroscopy and X-ray photoelectron spectroscopy (XPS, ULVAC-PHI, Tokyo, Japan). Raman spectrum of the as-prepared samples was measured using a Raman microscope (HR800, HORIBA, Tokyo, Japan).

\subsection{Electrochemical Analysis}

The energy storage performance of the samples was evaluated by fabricating the coin cells in an argon filled glovebox. The working electrode was prepared by mixing active material, polyvinylidene fluoride (PVdF), KS4 and Super P with a ratio of 8:0.5:0.5:1 in N-methyl-2pyrrolidone (NMP). The as-prepared slurry was cast onto a $\mathrm{Al}$ foil and then dried in a vacuum oven at $120{ }^{\circ} \mathrm{C}$ overnight. The electrolyte comprises $1.0 \mathrm{M} \mathrm{LiPF}_{6}$ dissolved in a mixture of ethylene carbonate and dimethyl carbonate at a volumetric ratio of 1:1. Cyclic voltammetry (CV) and electrochemical impedance spectroscopy (EIS) were carried out on a potentiostat (PARSTAT 4000 Potentiostat Galvanostat). The galvanostatic charge/discharge performance was examined between 1 and $2.5 \mathrm{~V}$ (vs. $\left.\mathrm{Li}^{+} / \mathrm{Li}\right)$ at various $\mathrm{C}$ rates $(1 \mathrm{C}=175 \mathrm{~mA} / \mathrm{g})$.

\section{Results and Discussion}

In general, the molecular packing of PI can be improved by using rigid $p$-PDA units to replace the rotatable ODA moiety. It has been reported that the regular PI with higher orientation degree of molecular chains can produce better graphite structure after a carbonization process [25]. Therefore, in this study, we prepared the carbon-coated LTO powders using the less-ordered PO-PI and more ordered POP-PI as carbon sources. POand POP-PI were synthesized through a conventional two-step polycondensation of PMDA dianhydride with ODA and $p$-PDA diamines and the reaction process is shown in Figure $1 \mathrm{a}$. The ultraviolet-visible (UV-vis) absorption spectra of the PO- and POP-PAA solutions are 
shown in Figure 1b. The inset in Figure $1 \mathrm{~b}$ presents the digital photograph of the PO- and POP-PAA solutions. The PO-PAA solution exhibits strong absorption in the UV region with an absorption edge of $410 \mathrm{~nm}$. With the incorporation of the PDA moiety into the polymer backbone, the absorption profile of POP-PAA tends to be shifted toward the long wavelength region. The red-shift of the absorption spectrum of POP-PAA can be explained by the formation of a charge transfer complex (CTC) between the alternating electron-acceptor (dianhydride) and electron-donor (diamine) moieties [26]. The $\mathrm{C}-\mathrm{O}-\mathrm{C}$ bond in ODA units can separate the chromaphoric centers and cut the electronic conjugations [27]. As a result, the PO-PAA shows a lighter color compared with that of POP-PAA due to its reduced intra-/intermolecular CTC formation. These results indicate that the PDA diamine units are successfully introduced into the copolymer. To study the effect of the $p$-PDA moiety on the imidization process, the enthalpy of imidization for the PO-PAA and POP-PAA was recorded by DSC measurement. As shown in Figure 1c, both the PAA samples exhibit a distinctive endothermic peak centered at around $175.5 \sim 179.8^{\circ} \mathrm{C}$ in the first run which originated from the imidization reaction. In the second run, the DSC curves show a smooth profile without any peak, indicating the imidization process is complete. In addition, the enthalpy of imidization integrated from the DSC curve (first run) was calculated to be 228.6 and $235.6 \mathrm{~J} / \mathrm{g}$ for PO-PAA and POP-PAA, respectively. The similar peak temperature and enthalpy of imidization for the two PAAs suggest that the incorporation of the $p$-PDA unit cannot alter the imidization behavior and the corresponding chemical conversion.
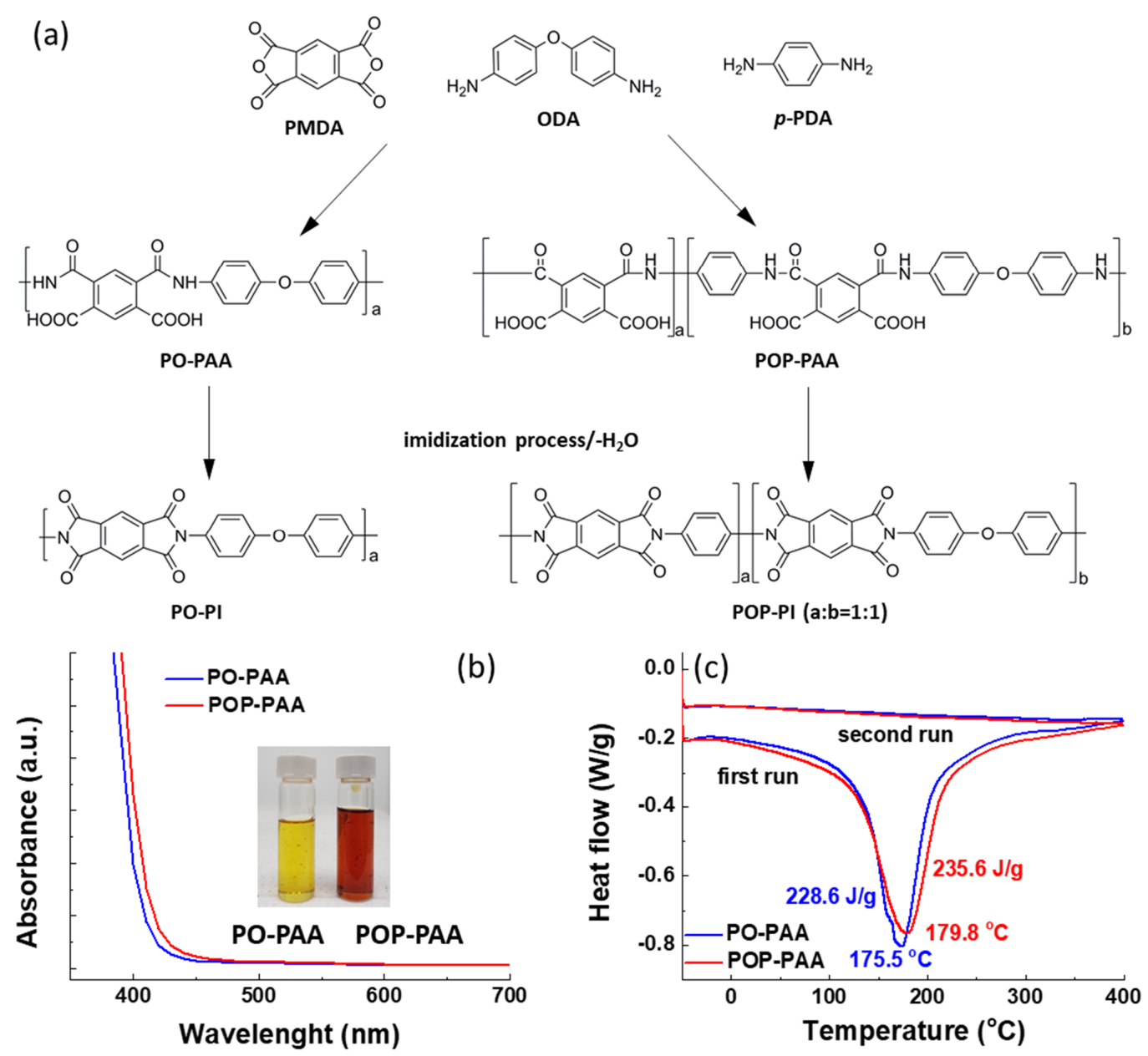

Figure 1. (a) The process of preparation of PMDA (pyromellitic dianhydride) and ODA (4,4'-oxydianiline) (PO-) and PMDA/ODA/p-phenylenediamine ( $p$-PDA) polyimide (POP-PI) with PMDA, ODA, and $p$-PDA; (b) the absorbance spectrum of PO- and POP-PAA solution and (c) the differential scanning calorimetry (DSC) profile of the PO- and POP-PAA (poly(amic acid)). 
The FTIR spectra of the as-prepared PAA and its corresponding PI are shown in Figure 2a. Both the two PAAs exhibit a broad band located at $1630 \mathrm{~cm}^{-1}$, which can be assigned to amide $\mathrm{C}=\mathrm{O}$ stretching mode $[28,29]$. After thermal treatment, this peak disappeared in the spectra of PO-PI and POP-PI (Figure 2b). Moreover, a new peak due to the $\mathrm{C}-\mathrm{N}-\mathrm{C}$ stretching vibration appears at $1365 \mathrm{~cm}^{-1}$ [30]. Meanwhile, the $\mathrm{C}=\mathrm{C}$ double bond in the benzene ring at around $1500 \mathrm{~cm}^{-1}$ remains unchanged after the imidization process. These results indicate that the two PAAs were successfully converted into PO-PI and POP-PI after the imidization process. The peak at $1234 \mathrm{~cm}^{-1}$ is characteristic of C-O-C stretching vibration belonging to the ODA moiety [25]. It is worth noting that the POPPAA and POP-PI reveal a much weaker intensity of $\mathrm{C}-\mathrm{O}-\mathrm{C}$ bond than their counterparts, confirming the successful incorporation of PDA moiety into the polymer backbone. The XPS O 1s and N 1s spectra of PO-PI are also shown in Figure 2c,d. After deconvolution, the $\mathrm{O}$ 1s XPS spectrum of the PO-PI can be fitted with two peak components assigned to $\mathrm{C}=\mathrm{O}$ and $\mathrm{C}-\mathrm{O}-\mathrm{C}$ species at 531.9 and $533.2 \mathrm{eV}$, respectively [31]. For the $\mathrm{N} 1 \mathrm{~s}$ spectrum of the PO-PI, only one characteristic peak contributed from $\mathrm{O}=\mathrm{C}-\mathrm{N}$ specie at $399.7 \mathrm{eV}$ can be obtained after deconvolution [32]. These results indicate that the PAA has been successfully converted into the PI structure after the thermal treatment.
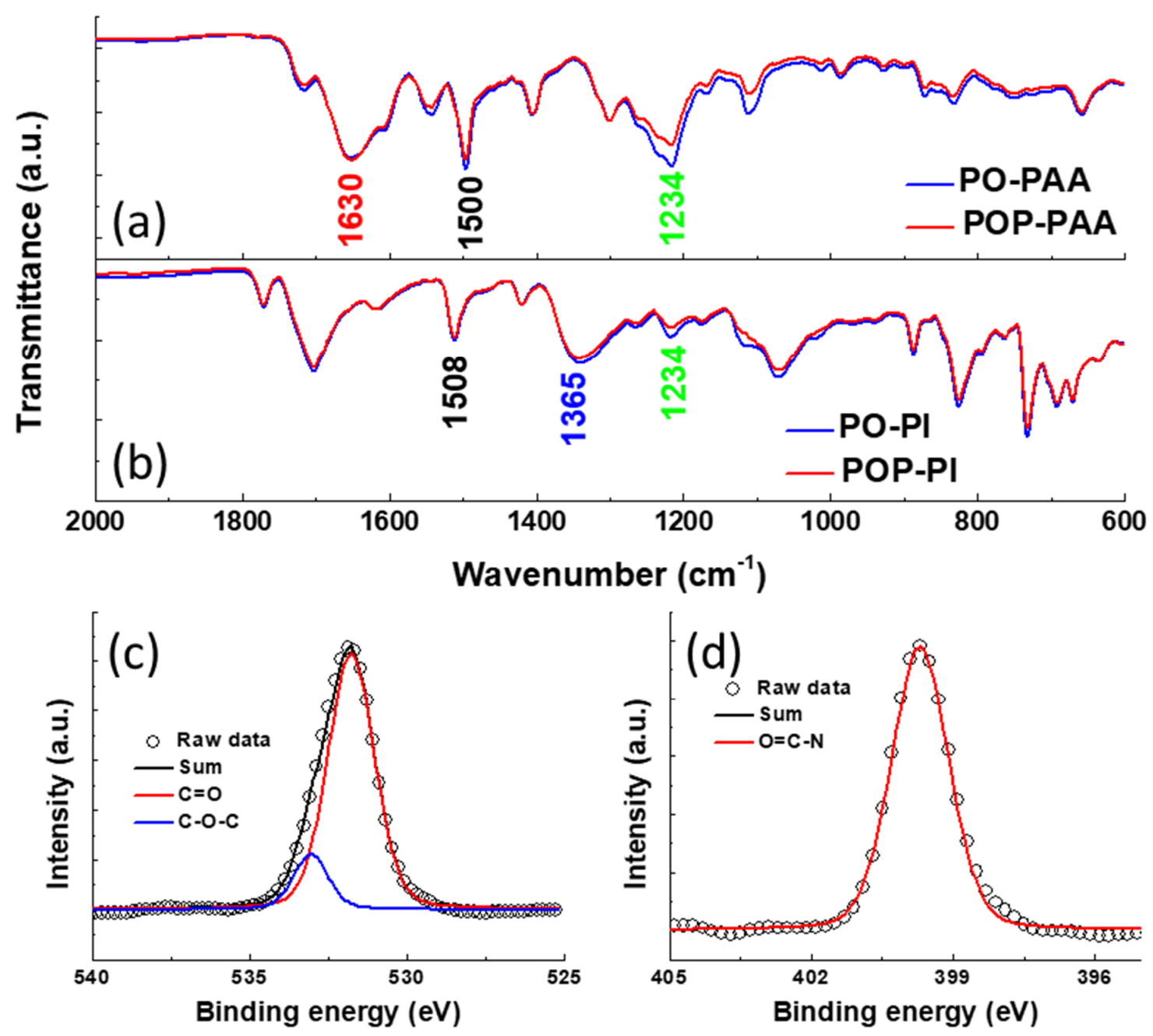

Figure 2. The Fourier transform infrared (FTIR) spectra of (a) PO-PAA and POP-PAA and (b) PO-PI and POP-PI; the peak deconvolution of the (c) O 1s and (d) N 1s X-ray photoelectron spectroscopy (XPS) spectra of the as-prepared PO-PI.

The microscopic molecular packing state of the PO- and POP-PI films was investigated by XRD measurement. As shown in Figure 3a, the XRD pattern of PO-PI is blunt without obvious diffraction signals, suggesting its amorphous nature. The amorphous state of 
PO-PI originated from the flexible ether linkage within the ODA unit which loosens the chain packing of the PO-PI. In contrast, incorporation of the $p$-PDA unit in the polymer backbone can significantly enhance the polymer chain stacking. The regularly ordered structure of POP-PI is attributed to the rigid and planar skeletal structure of $p$-PDA leading to the better crystallinity [33]. Figure $3 \mathrm{~b}$ compares the TGA curves of the PIs to investigate the thermal stability. Both the PI samples exhibit a major thermal decomposition ranging from 530 to $720{ }^{\circ} \mathrm{C}$. The $5 \mathrm{wt} \%$ thermal decomposition temperature $\left(T_{\mathrm{d}}\right)$ of the POP-PI is found to be $584^{\circ} \mathrm{C}$, which is higher than that of PO-PI $\left(576{ }^{\circ} \mathrm{C}\right)$, suggesting its better thermal stability of POP-PI. The improved thermal stability of POP-PI can be interpreted by the presence of the $p$-PDA group, which increases the intra- and interpolymer chain interactions, resulting in tight polymer chain packaging.
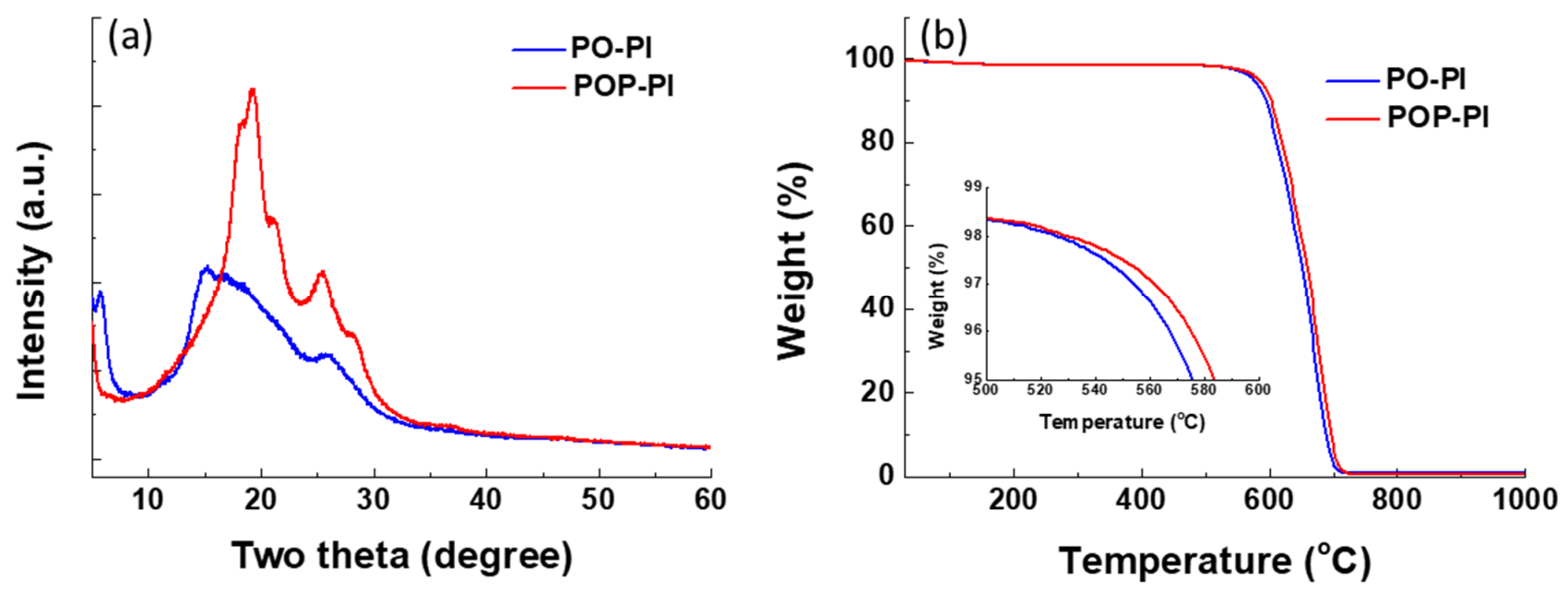

Figure 3. (a) The XRD patterns of PO-PI and POP-PI; (b) the TGA profile of the PO-PI and POP-PI.

Figure 4a displays the XRD pattern of the carbon materials derived from PO- and POPPI. The resultant carbon materials reveal two peaks located at 23.5 and $43.8^{\circ}$, indicating the development of (002) and (100) planes, respectively [34]. These results suggest that both the two PI samples can be converted into the hexagonal structures of the carbonized materials after the thermal treatment. Moreover, the POP-PI derived carbon exhibits much stronger XRD peaks than that derived from PO-PI, indicating its higher degree of graphitization. Figure $4 \mathrm{~b}$ shows the Raman spectra of the two carbonized materials to further provide atomic-scale structural information. The Raman spectrum of the two samples shows the characteristic $D$ band $\left(1342 \mathrm{~cm}^{-1}\right)$ and $G$ band $\left(1582 \mathrm{~cm}^{-1}\right)$, which correspond to the sp $\mathrm{sp}^{3}$ and $\mathrm{sp}^{2}$ carbon, respectively $[35,36]$. In general, the intensity ratio between the $\mathrm{D}$ band and $\mathrm{G}$ band $\left(\mathrm{I}_{\mathrm{D}} / \mathrm{I}_{\mathrm{G}}\right)$ can be used to determine the graphitization degree of the carbonized materials. The $\mathrm{I}_{\mathrm{D}} / \mathrm{I}_{\mathrm{G}}$ values of the PO- and POP-PI derived carbons are calculated to be 1.04 and 0.75 , respectively. The lower $\mathrm{I}_{\mathrm{D}} / \mathrm{I}_{\mathrm{G}}$ ratio of POP-PI derived carbon also suggests its more ordered structure and the increased $\mathrm{sp}^{2}$ content. The $\mathrm{C} 1 \mathrm{~s}$ XPS spectra of the POand POP-PI derived carbons are shown in Figure 4c, d to further characterize their chemical composition. Both the samples show four peaks with binding energies of 284.5, 285.4, 286.5 and $288.0 \mathrm{eV}$, which correspond to the functional groups of $\mathrm{C}=\mathrm{C}, \mathrm{C}-\mathrm{C}, \mathrm{C}-\mathrm{O}$ and $\mathrm{C}=\mathrm{O}$, respectively. Based on the XPS analysis, the proportions of $\mathrm{C}=\mathrm{C}$ for PO- and POP-PI derived carbons are $63.3 \%$ and $66.4 \%$, respectively. Conversely, the proportion of oxygen-containing functional groups $(\mathrm{C}-\mathrm{O}$ and $\mathrm{C}=\mathrm{O})$ of POP-PI based carbon $(6.98 \%)$ is lower than that of the PO-PI based one (10.77\%). In addition, the electronic conductivity of the PI derived carbons was directly measured with a four-point probe. The values of PO-PI and POP-PI derived carbons are 89.5 and $100.1 \mathrm{~S} / \mathrm{cm}$, respectively. These results further confirm that it is crucial to ensure the increased level of the structural arrangement of the initial PI precursor to prepare high-quality carbon materials with graphite-like structure [37]. 

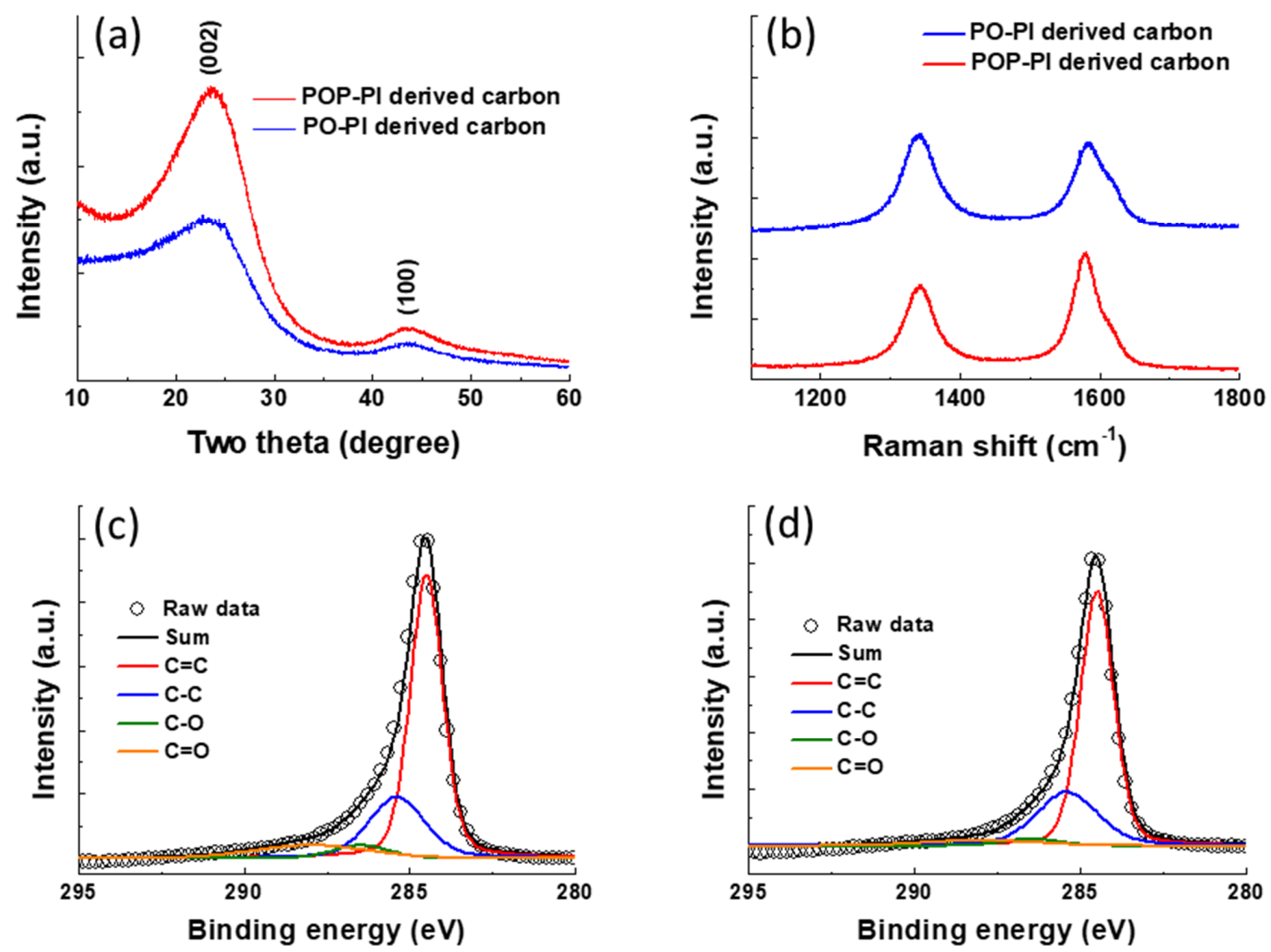

Figure 4. (a) The X-ray diffraction (XRD) pattern of the carbon materials derived from PO- and POP-PI; (b) Raman spectra of the carbon materials derived from PO- and POP-PI; peak deconvolution of the C 1s XPS spectra of (c) PO-PI derived carbon and (d) POP-PI derived carbon.

The XRD pattern of the spray-dried LTO powders is exhibited in Figure 5a. All the peaks between 5 and $70^{\circ}$ can be assigned to the spinel LTO structure without any impurity phases. The particle size distribution of the as-prepared LTO is shown in Figure 5b. The particle size of the LTO powders ranges between 1.88 and $27.4 \mu \mathrm{m}$ with a mean particle size of $10.7 \mu \mathrm{m}\left(D_{50}\right)$. The micro-sized particles can be favorable for the powder packing during the electrode fabrication leading to better energy density. The surface area of the LTO was also evaluated by the Brunauer-Emmett-Teller (BET) analysis as shown in Figure 5c. Based on the nitrogen adsorption/desorption isotherms, the surface area of the LTO was calculated to be $11.3 \mathrm{~m}^{2} / \mathrm{g}$. Figure $5 \mathrm{~d}$ displays the Ti $2 \mathrm{p}$ core level XPS spectrum of the as-prepared LTO samples. There are two pairs of Ti $2 \mathrm{p}$ peaks observed at $464.3,458.5$ and $462.2,456.4 \mathrm{eV}$ for $\mathrm{Ti}^{4+} 2 \mathrm{p}_{1 / 2}, \mathrm{Ti}^{4+} 2 \mathrm{p}_{3 / 2}$ and $\mathrm{Ti}^{3+} 2 \mathrm{p}_{1 / 2}, \mathrm{Ti}^{3+} 2 \mathrm{p}_{3 / 2}$, respectively. The partial reduction of the $\mathrm{Ti}$ ions from $\mathrm{Ti}^{4+}$ to $\mathrm{Ti}^{3+}$ originates from the generation of oxygen vacancies during the thermal annealing in $\mathrm{N}_{2}$ ambience [38]. The microstructure of the LTO was investigated by SEM observation. The low-magnification SEM examination as shown in Figure 5e reveals that the morphology of LTO sample is perfectly preserved as highly uniform microspheres. In addition, the enlarged SEM image (Figure 5f) shows that the surface of the microspheres is composed of a primary nanoparticle with an average size of around $80 \mathrm{~nm}$ leading to a porous surface. The porous structure can facilitate the ionic transport during the charge/discharge process.

The morphologies of the pristine and carbon-coated LTO are monitored by SEM and TEM as shown in Figure 6. It can be observed that the whole sample reveals similar SEM morphology, indicating the spherical structure can be maintained after the carbon coating process. Moreover, the high-resolution TEM images of the PO-LTO and POP-LTO show a carbon layer with a thickness of around $2 \mathrm{~nm}$ was uniformly deposited on the LTO surface. In contrast, no carbon layer can be observed for bare LTO. It has been reported that the carbon layer can offer a conductive pathway for the electron transport. In addition, the 
randomly distributed defects and vacancies within the carbon layer also can improve the $\mathrm{Li}^{+}$ ion migration [6]. As a result, the kinetic balance between the electronic and ionic transport can be established leading to better rate performance. The XPS survey of the POP-LTO and Raman spectrum of the three samples are also provided in the Supporting Information.
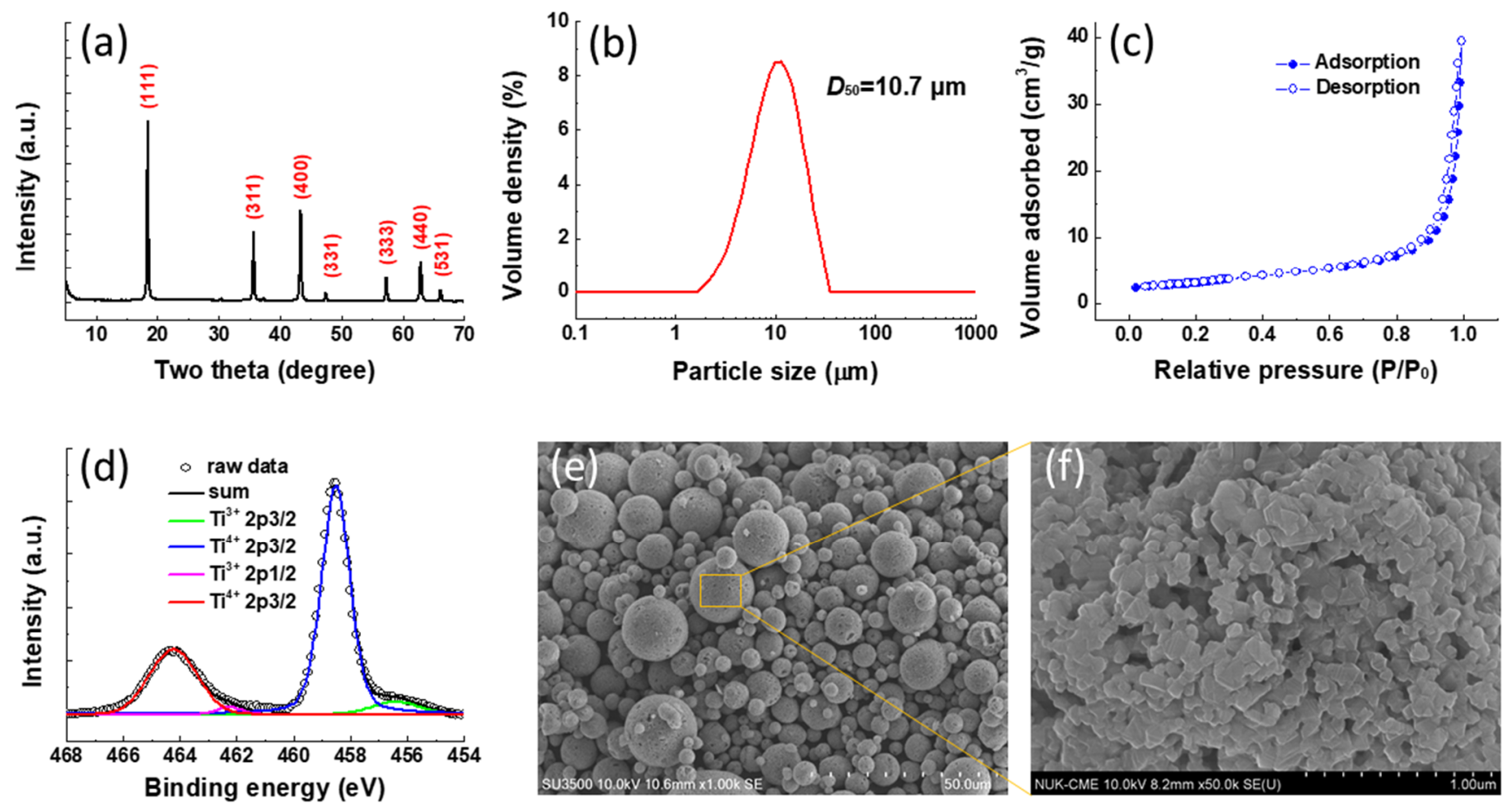

Figure 5. (a) The XRD pattern of the spray-dried $\mathrm{Li}_{4} \mathrm{Ti}_{5} \mathrm{O}_{12}$ (LTO) powder; (b) the particle size distribution of the LTO; (c) the nitrogen adsorption/desorption isotherms of the LTO; (d) peak deconvolution of the Ti 2p XPS spectrum of LTO powder; (e,f) scanning electron microscopy (SEM) images of the LTO with different magnifications.
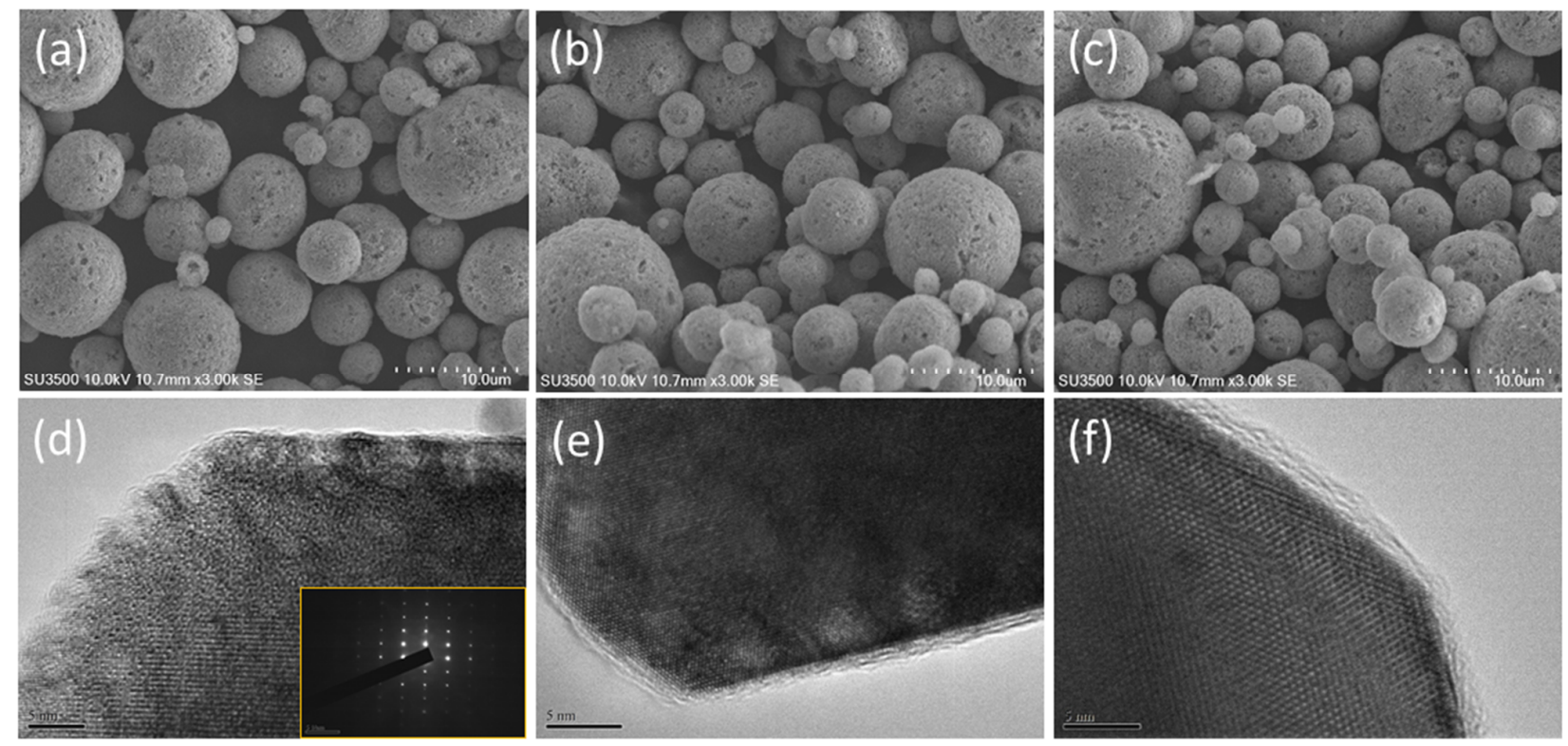

Figure 6. The SEM morphology of (a) bare LTO; (b) PO-LTO and (c) POP-LTO; the transmission electron microscopy (TEM) image of (d) bare LTO; (e) PO-LTO and (f) POP-LTO.

The electrochemical properties of the bare and carbon-coated LTO samples were studied by measuring their $\mathrm{CV}$ profiles with a scan rate of $1 \mathrm{mV} / \mathrm{s}$ between 1.0 and $2.5 \mathrm{~V}$ as 
shown in Figure 7a. All the samples reveal a pair of sharp redox couple which corresponds to the transition between $\mathrm{Li}_{4} \mathrm{Ti}_{5} \mathrm{O}_{12}$ and $\mathrm{Li}_{7} \mathrm{Ti}_{5} \mathrm{O}_{12}$. The separation between the anodic and cathodic peaks $(\Delta \mathrm{E})$ of the LTO would be dramatically reduced with the incorporation of carbon coating, indicating the reduction of polarization. The $\Delta \mathrm{E}$ of LTO, PO-LTO and POP-LTO is found to be $0.7,0.63$ and $0.52 \mathrm{~V}$, respectively. The lower polarization is mainly attributed to the enhancement of electric conductivity by the interfacial carbon modification. As shown in Figure 4, the POP based carbon layer shows a more regular graphite structure with a higher conductivity $(100.1 \mathrm{~S} / \mathrm{cm})$ than that of $\mathrm{PO}$ based carbon layer $(89.5 \mathrm{~S} / \mathrm{cm})$. As a result, the POP-LTO reveals a much lower polarization $(0.52 \mathrm{~V})$ due than that of PO-LTO $(0.63 \mathrm{~V})$. Furthermore, the EIS spectra of the three electrodes were taken to investigate the interfacial impedance in the electrodes. Figure $7 \mathrm{~b}$ shows the Nyquist plots of LTO, PO-LTO and POP-LTO electrodes with a frequency range from $10^{5} \mathrm{~Hz}$ to $10^{-2} \mathrm{~Hz}$ at an amplitude of $10 \mathrm{mV}$. All the plots exhibit a semicircle with a sloping line. The charge transfer resistance $(R c t)$ determined from the size of the semicircle in the high frequency is around 117, 43.7 and $21.5 \Omega$ for LTO, PO-LTO and POP-LTO, respectively. The Rct of POP-LTO is much lower than that of the bare one due to the deposition of the conductive carbon layer. The rate performance of the three electrodes evaluated at various $C$ rates is displayed in Figure 7c. As expected, the POP-LTO with the modification of the POP-PI derived carbon layer can deliver the best rate capability due to its low polarization and Rct. The POP-LTO shows a high capacity retention of $83.2 \%(137.5 \mathrm{mAh} / \mathrm{g})$ at a high rate of $20 \mathrm{C}$, which is higher than 70.7\% (115.3 mAh/g) and 58.5\% (94.4 mAh/g) for PO-LTO and pristine LTO, respectively. The corresponding charge/discharge profiles of the POP-LTO with different $C$ rates are also provided in Figure $7 d$. The comparison of LTO performance with different carbon coating is also summarized in the Supporting Information.
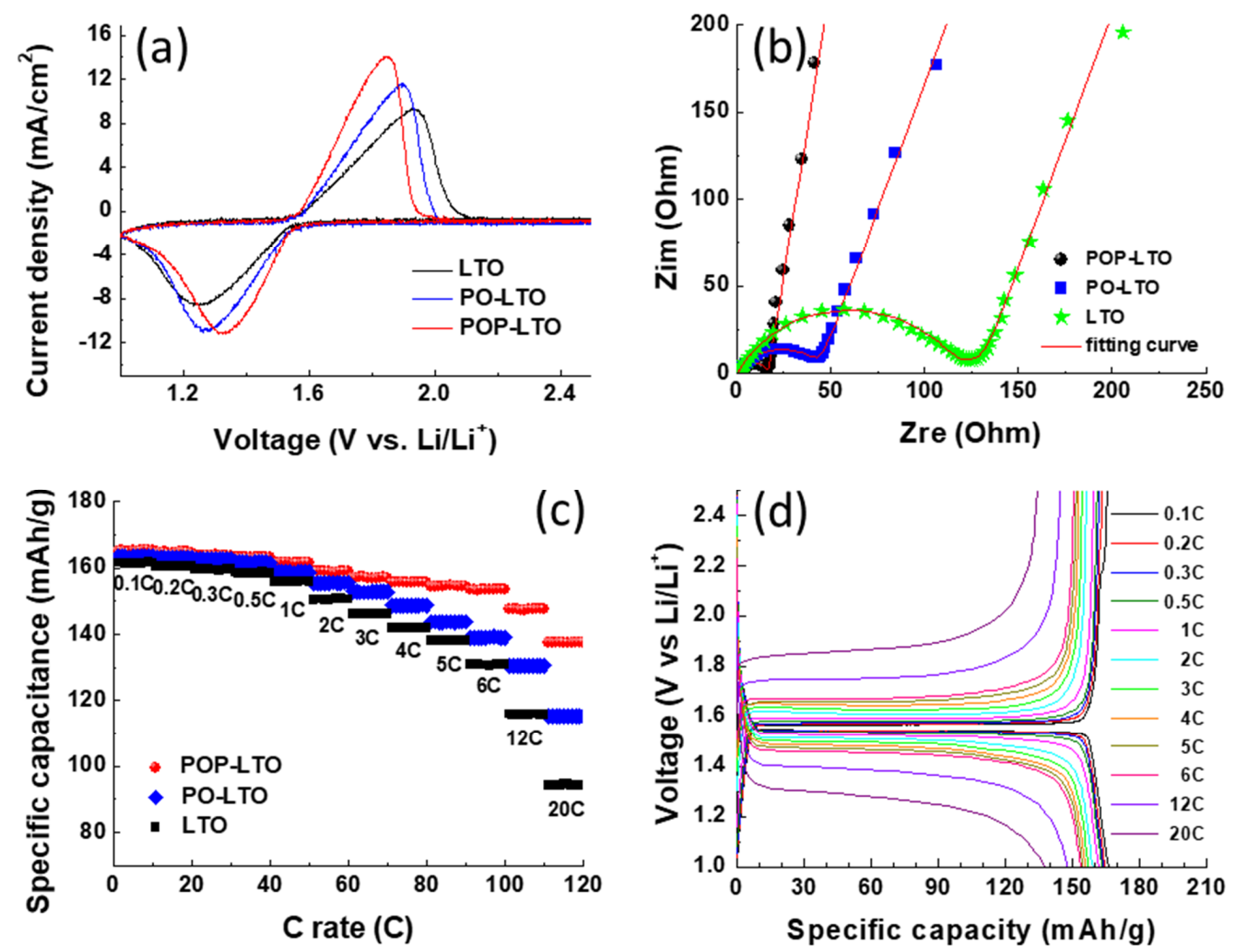

Figure 7. (a) The cyclic voltammetry (CV) curves of bare LTO, PO-LTO and POP-LTO stepped between 1.0 and $2.5 \mathrm{~V}$ with a scan rate of $1 \mathrm{mV} / \mathrm{s}$; (b) Nyquist plots of bare LTO, PO-LTO and POP-LTO in the frequency range of $10^{5} \mathrm{~Hz}$ to $10^{-2} \mathrm{~Hz}$; (c) rate capability of the as-prepared samples at $\mathrm{C}$ rates between $0.1 \mathrm{C}$ and $20 \mathrm{C}$; (d) the corresponding charge/discharge profile of the POP-LTO with various $C$ rates. 


\section{Conclusions}

In summary, a facile and scalable method has been developed for synthesizing carboncoated LTO, using PI as the carbon source. After carbonization treatment at $800{ }^{\circ} \mathrm{C}$ in $\mathrm{N}_{2}$ ambience, the PI coating can be transferred into the high-conductive carbon layer. The nano-carbon layer on LTO can improve both the electronic and ionic conductivities. As compared to pristine LTO, results show that the POP-LTO exhibits substantially improved cell performances particularly in the rate capability. A high initial discharge capacity of $165.1 \mathrm{mAh} / \mathrm{g}$ is delivered at $0.1 \mathrm{C}$ and the specific capacity still maintain $137.5 \mathrm{mAh} / \mathrm{g}$ even at $20 \mathrm{C}$. It is believed that the developed method also can be extended to improve the electrochemical performances of other alternative LIB materials with low intrinsic electrical conductivity and poor $\mathrm{Li}^{+}$diffusion coefficient.

Supplementary Materials: The following are available online at https://www.mdpi.com/article/10 $.3390 /$ polym13111672/s1, Figure S1: The XPS survey of the POP-LTO and the corresponding atomic percentages, Figure S2: Raman spectrum of the pristine LTO, PO-LTO and POP-LTO, Table S1: The comparison of LTO performance with different carbon coating.

Author Contributions: Writing —original draft preparation, S.-C.H.; writing—review and editing, T.-T.H. and T.-Y.L.; resources, Y.-J.W.; resources, C.-Z.L.; supervision, H.C.W.; conceptualization, J.-H.H.; investigation, C.-W.C.-J. and T.-Y.L.; funding acquisition, T.-Y.L. All authors have read and agreed to the published version of the manuscript.

Funding: This research received no external funding.

Acknowledgments: We are grateful to the Ministry of Science and Technology (MOST 104-2113-M152-001-MY2, MOST 105-2320-B-038-014-) and CPC Corporation (105-3011). for financial support. We would also like to thank the research funding from Taipei Medical University (TMU102-AE1-B02, TMUTOP103004-2). The research endeavors at Ming Chi University of Technology were supported in part by the Ministry of Science and Technology (MOST 103-2221-E-131-002-MY2), by the Chang Gung Memorial Hospital, Linkou, Taiwan (CMRPG3E2091), and by the Academia Sinica Research Project on Thematic Project (AS-104-TP-A11).

Conflicts of Interest: The authors declare no conflict of interest.

\section{References}

1. Ding, Y.; Cano, Z.P.; Yu, A.; Lu, J.; Chen, Z. Automotive Li-ion batteries: Current status and future perspectives. Electrochem. Energy Rev. 2019, 2, 1-28. [CrossRef]

2. Zhang, Q.; $\mathrm{Li}, \mathrm{X}$. Recent developments in the doped- $\mathrm{Li}_{4} \mathrm{Ti}_{5} \mathrm{O}_{12}$ anode materials of lithium-ion batteries for improving the rate capability. Int. J. Electrochem. Sci. 2013, 8, 6449-6456.

3. Wu, L.; Leng, X.; Liu, Y.; Wei, S.; Li, C.; Wang, G.; Lian, J.; Jiang, Q.; Nie, A.; Zhang, T.Y. A strategy for synthesis of nanosheets consisting of alternating spinel $\mathrm{Li}_{4} \mathrm{Ti}_{5} \mathrm{O}_{12}$ and rutile $\mathrm{TiO}_{2}$ lamellas for high-rate anodes of lithium-ion batteries. ACS Appl. Mater. Interfaces 2017, 9, 4649-4657. [CrossRef] [PubMed]

4. Jiang, Y.M.; Wang, K.X.; Wu, X.Y.; Zhang, H.J.; Bartlett, B.M.; Chen, J.S. $\mathrm{Li}_{4} \mathrm{Ti}_{5} \mathrm{O}_{12} / \mathrm{TiO}_{2}$ hollow spheres composed nanoflakes with preferentially exposed $\mathrm{Li}_{4} \mathrm{Ti}_{5} \mathrm{O}_{12}$ (011) facets for high-rate lithium ion batteries. ACS Appl. Mater. Interfaces 2014, 6, 19791-19796. [CrossRef]

5. Park, K.S.; Benayad, A.; Kang, D.J.; Doo, S.G. Nitridation-driven conductive $\mathrm{Li}_{4} \mathrm{Ti}_{5} \mathrm{O}_{12}$ for lithium ion batteries. J. Am. Chem. Soc. 2008, 130, 14930-14931. [CrossRef] [PubMed]

6. $\quad$ Long, D.H.; Jeong, M.G.; Lee, Y.S.; Choi, W.; Lee, J.K.; Oh, I.H.; Jung, H.G. Coating lithium titanate with nitrogen-doped carbon by simple refluxing for high-power lithium-ion batteries. ACS Appl. Mater. Interfaces 2015, 7, 10250-10257. [CrossRef] [PubMed]

7. Jo, M.R.; Nam, K.M.; Lee, Y.; Song, K.; Park, J.T.; Kang, Y.M. Phosphidation of $\mathrm{Li}_{4} \mathrm{Ti}_{5} \mathrm{O}_{12}$ nanoparticles and their electrochemical and biocompatible superiority for lithium rechargeable batteries. Chem. Commun. 2011, 47, 11474-11476. [CrossRef] [PubMed]

8. Cao, L.; Kou, L.; Li, J.; Huang, J.; Yang, J.; Wang, Y. Nitrogen-doped carbon-coated $\mathrm{V}_{2} \mathrm{O}_{5}$ nanocomposite as cathode materials for lithium-ion battery. J. Mater. Sci. 2018, 53, 10270-10279. [CrossRef]

9. Kim, T.; Kim, H.; You, T.S.; Kim, J. Carbon-coated $\mathrm{V}_{2} \mathrm{O}_{5}$ nanoparticles derived from metal-organic frameworks as a cathode material for rechargeable lithium batteries. J. Alloys Compd. 2017, 727, 522-530. [CrossRef]

10. Lu, Q.; Jianhua Fang, J.; Yang, J.; Feng, X.; Wang, J.; Nuli, Y. A polyimide ion-conductive protection layer to suppress side reactions on $\mathrm{Li}_{4} \mathrm{Ti}_{5} \mathrm{O}_{12}$ electrodes at elevated temperature. RSC Adv. 2014, 4, 10280-10283. [CrossRef]

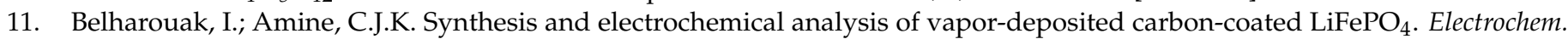
Commun. 2005, 7, 983-988. [CrossRef] 
12. Chen, Z.; Dahn, J.R. Reducing carbon in $\mathrm{LiFePO}_{4} / \mathrm{C}$ composite electrodes to maximize specific energy, volumetric energy, and tap density. J. Electrochem. Soc. 2002, 149, A1184-A1189. [CrossRef]

13. Cho, J.; Kim, Y.J.; Park, B. Novel $\mathrm{LiCoO}_{2}$ cathode material with $\mathrm{Al}_{2} \mathrm{O}_{3}$ coating for a Li ion cell. Chem. Mater. 2000, 12, 3788-3791. [CrossRef]

14. Jang, S.B.; Kang, S.H.; Amine, K.; Bae, Y.C.; Sun, Y.K. Synthesis and improved electrochemical performance of $\mathrm{Al}(\mathrm{OH})_{3}$-coated $\mathrm{Li}\left[\mathrm{Ni}_{1 / 3} \mathrm{Mn}_{1 / 3} \mathrm{Co}_{1 / 3}\right] \mathrm{O}_{2}$ cathode materials at elevated temperature. Electrochim. Acta 2005, 50, 4168-4173. [CrossRef]

15. Appapillai, A.T.; Mansour, A.N.; Cho, J.; Shao-Horn, Y. Microstructure of $\mathrm{LiCoO}_{2}$ with and without "AlPO 4 " nanoparticle coating: Combined STEM and XPS studies. Chem. Mater. 2007, 19, 5748-5757. [CrossRef]

16. Ying, J.; Wan, C.; Jiang, C. Surface treatment of $\mathrm{LiNi}_{0.8} \mathrm{Co}_{0.2} \mathrm{O}_{2}$ cathode material for lithium secondary batteries. J. Power Sources 2001, 102, 162-166. [CrossRef]

17. Li, H.; Zhou, H. Enhancing the performances of Li-ion batteries by carbon-coating: Present and future. Chem. Commun. 2012, 48, 1201-1217. [CrossRef]

18. Lin, J.; Peng, Z.; Liu, Y.; Ruiz-Zepeda, F.; Ye, R.; Samuel, E.L.G.; Yacaman, M.J.; Yakobson, B.I.; Tour, J.M. Laser-induced porous graphene films from commercial polymers. Nat. Commun. 2014, 5, 5714. [CrossRef]

19. Ye, R.; James, D.K.; Tour, J.M. Laser-induced graphene. Acc. Chem. Res. 2018, 51, 1609-1620. [CrossRef]

20. Inagaki, M.; Harada, S.; Sato, T.; Nakajima, T.; Horino, Y.; Morita, K. Carbonization of polyimide film “Kapton”. Carbon 1989, 27, 253-257. [CrossRef]

21. Peng, Z.; Ye, R.; Mann, J.A.; Zakhidov, D.; Li, Y.; Smalley, P.R.; Lin, J.; Tour, J.M. Flexible boron-doped laser induced graphene microsupercapacitors. ACS Nano 2015, 9, 5868-5875. [CrossRef] [PubMed]

22. Carvalho, A.F.; Fernandes, A.J.S.; Leitão, C.; Deuermeier, J.; Marques, A.C.; Martins, R.; Fortunato, E.; Costa, F.M. Laser-induced graphene strain sensors produced by ultraviolet irradiation of polyimide. Adv. Funct. Mater. 2018, 28, 1805271. [CrossRef]

23. Zhang, J.; Ren, M.; Wang, L.; Li, Y.; Yakobson, B.I.; Tour, J.M. Oxidized laser-induced graphene for efficient oxygen electrocatalysis. Adv. Mater. 2018, 30, 1707319. [CrossRef] [PubMed]

24. Bobinger, M.R.; Romero, F.J.; Salinas-Castillo, A.; Becherer, M.; Lugli, P.; Morales, D.P.; Rodríguez, N.; Rivadeneyra, A. Flexible and robust laser-induced graphene heaters photothermally scribed on bare polyimide substrates. Carbon 2019, 144, 116-126. [CrossRef]

25. Cao, L.; Zhang, M.; Niu, H.; Chang, J.; Liu, W.; Yang, H.; Cao, W.; Wu, D. Structural relationship between random copolyimides and their carbon fibers. J. Mater. Sci. 2017, 52, 1883-1897. [CrossRef]

26. Ando, S.; Matsuura, T.; Sasaki, S. Coloration of aromatic polyimides and electronic properties of their source materials. Polym. J. 1997, 29, 69-76. [CrossRef]

27. Matsuura, T.; Hasuda, Y.; Nishi, S.; Yamadat, N. Polyimide derived from 2,2'-Bis(trifluoromethyl)-4,4'-diaminobiphenyl.1. Synthesis and characterization of polyimides prepared with 2,2-Bis(3,4-dicarboxyphenyl)hexafluoropropane dianhydride or pyromellitic dianhydride. Macromolecules 1991, 24, 5001-5005. [CrossRef]

28. Kim, S.; Jang, K.S.; Choi, H.D.; Choi, S.H.; Kwon, S.J.; Kim, I.D.; Lim, J.A.; Hong, J.M. Porous polyimide membranes prepared by wet phase inversion for use in low dielectric applications. Int. J. Mol. Sci. 2013, 24, 8698-8707. [CrossRef] [PubMed]

29. Jeong, K.M.; Li, Y.; Yoo, D.G.; Lee, N.K.; Lee, H.G.; Ando, S.; Ha, C.S. Effects of crosslinking agents on the physical properties of polyimide/amino-functionalized graphene oxide hybrid films. Polym. Int. 2018, 67, 588-597. [CrossRef]

30. Ji, D.; Li, T.; Zou, Y.; Chu, M.; Zhou, K.; Liu, J.; Tian, G.; Zhang, Z.; Zhang, X.; Li, L.; et al. Copolymer dielectrics with balanced chain-packing density and surface polarity for high-performance flexible organic electronics. Nat. Commun. 2018, 9, 2339. [CrossRef] [PubMed]

31. Ektessabi, A.N.; Hakamata, S. XPS study of ion beam modified polyimide films. Thin Solid Film. 2000, 377-378, 621-625. [CrossRef]

32. Liu, J.N.; Sil, M.C.; Cheng, R.; Feng, S.P.; Chen, C.M. Surface silanization of polyimide for autocatalytic metallization. JOM 2020, 72, 3529-3537. [CrossRef]

33. Wang, J.; Zhao, X.; Berda, E.B.; Chen, C.; Wang, K.; Chen, S.; Zou, B.; Liu, B.; Zhou, Q.; Li, F.; et al. The elastic properties and piezochromism of polyimide films under high pressure. Polymer 2016, 90, 1-8. [CrossRef]

34. Zhang, M.Y.; Niu, H.Q.; Qi, S.L.; Tian, G.F.; Wang, X.D.; Wu, D.Z. Structure evolutions involved in the carbonization of polyimide fibers with different chemical constitution. Mater. Today Commun. 2014, 1, 1-8. [CrossRef]

35. Ferrari, A.C.; Robertson, J. Interpretation of Raman spectra of disordered and amorphous carbon. Phys. Rev. B 2000, 61, 14095. [CrossRef]

36. Sarno, M.; Baldino, L.; Scudieri, C.; Cardea, S.; Ciambelli, P.; Reverchon, E. SC-CO $\mathrm{C}_{2}$ assisted process for high energy density aerogel supercapacitor: The effect of GO loading. Nanotechnology 2017, 28, 204001. [CrossRef] [PubMed]

37. Smirnova, V.E.; Gofman, I.V.; Maritcheva, T.A.; Yudin, V.E.; Eto, K.; Takeichi, T.; Kaburagi, Y.; Hishiyama, Y. The effect of different orientations in rigid rod polyimide films on the graphitized products. Carbon 2007, 45, 839-846. [CrossRef]

38. Song, H.; Jeong, T.G.; Moon, Y.H.; Chun, H.H.; Chung, K.Y.; Kim, H.S.; Cho, B.W.; Kim, Y.T. Stabilization of oxygen-deficient structure for conducting $\mathrm{Li}_{4} \mathrm{Ti}_{5} \mathrm{O}_{12-\delta}$ by molybdenum doping in a reducing atmosphere. Sci. Rep. 2014, 4, 4350. [CrossRef] 